\title{
LEGO SERIOUS PLAY NA SOLUÇÃO DE PROBLEMAS FAMILIARES E SOCIETÁRIOS
}

\author{
Frederico de Andrade Gabrich ${ }^{1}$ \\ Luiza Machado Farhat Benedito ${ }^{2}$
}

\section{RESUMO:}

Muitas empresas do Brasil são familiares e quase todas vivenciam os mesmos problemas decorrentes da deficiência de planejamento e de estruturação da família e de suas sociedades. Apesar de o direito nascer no fato jurídico (que cria, extingue ou modifica direitos e obrigações), o ensino e a prática do direito de família e do direito empresarial societário quase sempre desconsideram essas situações fáticas. O LEGO Serious Play é um método de ensino e de trabalho, baseado no contrucionismo e na solução de problemas, que pode e deve ser usado no ensino e na prática jurídica.

PALAVRAS-CHAVE: Conflitos Familiares Societários; Metodologias de Ensino e Práticas Jurídicas; Inovação; Lego Serious Play.

\section{LEGO SERIOUS PLAY IN THE SOLUTION OF FAMILY AND COMPANY PROBLEMS}

\begin{abstract}
:
Many companies in Brazil are familiar and almost all of them experience the same problems due to the lack of planning and structuring of the family and its societies. Although the law is born in the legal fact (which creates, extinguishes or modifies rights and obligations), the teaching and practice of family law and corporate law almost always disregard these factual situations. LEGO Serious Play is a teaching and work method based on construction and problem solving that can and should be used in teaching and legal practice.
\end{abstract}

KEY-WORDS: Corporate Family Conflicts; Teaching Methodologies and Legal Practices; Innovation; Lego Serious Play.

\section{INTRODUÇÃO ${ }^{3}$}

Parte significativa das empresas do mundo são consideradas empresas familiares, pois a pessoa natural que fundou ou comprou a empresa também a controla nominal e efetivamente, detendo de maneira permanente a maioria dos votos nas reuniões e/ou nas

\footnotetext{
1 Doutor, Mestre e Especialista em Direito Empresarial/Comercial pela UFMG. Professor Adjunto da Universidade FUMEC. Coordenador do projeto de pesquisa Design Instrucional e Inovação das Metodologias de Ensino Jurídico (FAPEMIG).

${ }^{2}$ Mestra em Direito pela Universidade FUMEC. Especializada em Procedimentos de Mediação. Pesquisadora no projeto de pesquisa Design Instrucional e Inovação das Metodologias de Ensino Jurídico (FAPEMIG).

${ }^{3}$ Os autores agradecem o apoio recebido da Fundação de Amparo à Pesquisa do Estado de Minas Gerais FAPEMIG e da Universidade Fumec, para realização da pesquisa e divulgação dos seus resultados.
} 
assembleias dos sócios, elegendo a maioria dos administradores e usando o seu poder para dirigir os negócios sociais. Além disso, são consideradas empresas familiares aquelas nas quais pelo menos uma pessoa da família está envolvida diretamente na gestão dos negócios, e/ou, no caso da companhia aberta, quando a pessoa que a fundou ou adquiriu a empresa (ou a sua família) detém mais de $25 \%$ (vinte e cinco por cento) das ações com direito a voto e há pelo menos um membro da família na diretoria e/ou no conselho de administração.

De fato, todas (ou quase todas) as empresas familiares, um dia, cedo ou tarde, encontram-se diante de uma encruzilhada que aponta apenas três caminhos possíveis para os negócios da empresa e da família: “crescer", "vender" ou "morrer". Nesse momento, “crescer" geralmente significa estabelecer e implementar um planejamento estratégico objetivo, bem como estratégias de governança corporativa, de gestão profissional, de crescimento orgânico - mediante o crescimento das vendas, dos estabelecimentos, dos empregados etc - ou de crescimento inorgânico - por meio de associações estratégicas com outras empresas, fusão e/ou aquisição. Por outro lado, "vender" quase sempre implica a transferência do controle ou de participação societária significativa, combinada com a transferência da gestão (financeira e administrativa) ou dos estabelecimentos e pode ser o caminho menos doloroso para a incapacidade de a empresa se adequar aos novos tempos, de resolver as suas idiossincrasias e/ou abrigar os novos membros da família (pois normalmente a família acaba crescendo exponencialmente mais do que os negócios da própria empresa familiar). Finalmente, "morrer" quase sempre é consequência da incapacidade psicológica, estratégica e/ou financeira de "crescer" ou de "vender", bem como de solucionar uma série quase infinita de conflitos familiares (de ordem psíquica, relacional, amorosa, financeira, jurídica, administrativa etc) que atingem (de morte) a família e os negócios da empresa familiar.

Apesar de ser sabido que o direito nasce no fato jurídico (que cria, extingue ou modifica direitos e obrigações das pessoas), o ensino e a prática do direito de família e do direito empresarial societário quase sempre desconsideram as situações fáticas acima identificadas, que são relativamente comuns às famílias empreendedoras, às empresas e às sociedades familiares. Em regra, o ensino e a prática jurídica em geral e do direito de família e do direito empresarial societário em particular, continuam fundamentalmente instrucionistas, focado no saber do professor e/ou do profissional do direito, e baseado sobretudo na análise gramatical e conceitual dos textos da lei, com algumas abordagens jurisprudenciais pontuais. 
Por isso, o ensino do direito de família e do direito empresarial societário geralmente não aborda os conflitos familiares societários, bem como os instrumentos possíveis para a prevenção e a solução estratégica dos mesmos, preferencialmente sem o uso dos meios judiciais. E isso acaba repercutindo na prática dos profissionais do direito. Este é o problema que esta pesquisa procura enfrentar, por meio do método dedutivo e com fundamento nos referenciais teóricos estabelecidos por Per Kristiansen e Robert Rasmussen, na obra: Construindo um negócio melhor com a utilização do método Lego Serious Play; por Matheus Bonaccorsi Fernandino, na obra: Governança Jurídica nas Empresa Familiares; e por Frederico de Andrade Gabrich, na obra: Análise Estratégica do Direito.

\section{AS EMPRESAS FAMILIARES E OS PRINCIPAIS PROBLEMAS ENFRENTADOS POR ELAS}

O conceito de empresa é econômico e não jurídico. Assim, geralmente, considera-se empresa a atividade econômica organizada profissionalmente para a produção e/ou para a circulação de bens, de serviços e de pessoas.

Por isso, uma empresa é a organização do capital e do trabalho, realizada por meio de uma pessoa (natural ou jurídica), que pode ser, especificamente no âmbito do direito empresarial, um empresário individual (com ou sem registro), uma empresa individual de responsabilidade limitada (EIRELI), uma sociedade em comum, uma sociedade em conta de participação, uma sociedade em nome coletivo, uma sociedade em comandita simples, uma sociedade limitada, uma sociedade anônima ou uma sociedade em comandita por ações, tal como estabelecido pelo Código Civil brasileiro.

De fato, uma empresa pode ser organizada juridicamente por uma dessas formas e pode estabelecer-se por meio de um ou de vários estabelecimentos, que são universalidades de fato (conjunto de bens, sem personalidade jurídica própria), definidos pelo disposto no artigo 1.142 do Código Civil, da seguinte maneira:

Considera-se estabelecimento todo complexo de bens organizado, para exercício da empresa, por empresário, ou por sociedade empresária (BRASIL, 2002).

Geralmente, considera-se que uma empresa é familiar quando a pessoa natural que a fundou ou comprou também a controla nominal e efetivamente, detendo (diretamente ou por 
meio de sua família) de maneira permanente a maioria dos votos nas reuniões e/ou nas assembleias dos sócios, elegendo a maioria dos administradores e usando o seu poder para dirigir os negócios sociais. Além disso, são consideradas empresas familiares aquelas nas quais pelo menos uma pessoa da família está envolvida diretamente na gestão dos negócios, e/ou, no caso da companhia aberta, quando a pessoa que a fundou ou adquiriu a empresa (ou a sua família) detém mais de $25 \%$ (vinte e cinco por cento) das ações com direito a voto e há pelo menos um membro da família na diretoria e/ou no conselho de administração.

Não é, portanto, a forma jurídico-societária, o faturamento ou o porte de uma empresa que a faz ser considerada como familiar ou não. O que determina isso é o fato de uma mesma pessoa ou família controlar direta ou indiretamente a empresa (composta por uma ou várias sociedades), possuindo o controle nominal (maioria das quotas ou ações com direito a voto) e/ou o controle efetivo (direito de eleger a maioria dos administradores e uso efetivo do poder para gerir os negócios da empresa).

Várias estatísticas publicadas nos últimos anos pelo $\operatorname{Sebrae}^{4}$ e outras instituições de pesquisa, apontam que cerca de $90 \%$ (noventa por cento) das empresas brasileiras são controladas por pessoas de uma mesma família, mas que apenas 30\% (trinta por cento) dessas empresas sobrevivem até a segunda geração e que somente $5 \%$ (cinco por cento) dessas organizações chegam à terceira geração (FERNANDINO, 2016). Dentre vários fatores, isso geralmente acontece porque, alternativa ou conjuntamente: os conflitos interpessoais da família afetam a organização da empresa familiar; as contas pessoais dos sócios são pagas pela empresa; a contabilidade está atrasada; existe briga familiar e/ou a sucessão foi mal resolvida; o cunhado 'trabalha' na empresa; o filho recebe da empresa e não trabalha; as despesas da fazenda são pagas pela sociedade; os sócios não têm remuneração fixa; a empregada doméstica é paga pela empresa; a mesada da mãe/pai/avó é paga pela empresa; ninguém tem coragem de dizer para o patriarca/matriarca as verdades; a empresa é cabide de emprego da família; não há controle de custos, nem metodologia para formação de preços; há sonegação de impostos; a gestão é absolutamente amadora; não há orçamento; não há planejamento estratégico; o software de gestão não existe ou não é usado adequadamente; não há análise da concorrência etc (FERNANDINO, 2016).

\footnotetext{
${ }^{4}$ Disponível em: <http://www.sebrae-sc.com.br/newart/default.asp?materia=10410>. Acesso em 13 de maio de 2017.
} 
Pior. Isso acontece também porque não existe nenhum tipo de governança jurídica estabelecida de forma estratégica e customizada para a realização mais eficiente dos objetivos da família empreendedora, das empresas e sociedades familiares.

Nesse sentido, quase todos os casamentos e uniões estáveis acontecem na família empreendedora sem a devida discussão do regime de bens a ser adotado, e das consequências disso para os negócios da família.

Da mesma maneira, normalmente não há a devida preocupação com a antecipação da sucessão patrimonial e as pessoas desconhecem as vantagens pessoais e tributárias deste tipo de planejamento sucessório. Nesse sentido, geralmente as pessoas da família empreendedora desconhecem completamente as possibilidades de sucessão em vida dos bens imóveis, por exemplo, por meio de sociedade holding patrimonial combinada com um acordo de quotistas/acionistas, nem tampouco as possibilidades de sucessão em vida dos recursos financeiros (dinheiro), por exemplo, por meio de fundos de investimento financeiros exclusivos.

A deficiência ou ausência da governança jurídica nessas famílias empreendedoras e nas suas empresas também fica evidente porque geralmente não há a devida atenção para a importância do planejamento jurídico e administrativo estratégico necessário para a devida sucessão da administração dos negócios da família, por meio da capacitação e preparação de familiares, ou por intermédio da profissionalização da gestão empresarial (GABRICH, 2010).

Além disso, os modelos contratuais societários normalmente são padronizados, elaborados sem qualquer rigor científico (mediante o uso indiscriminado de formulários de contratos padronizados), sem a realização de um briefing (por profissional qualificado e habilitado para isso), e, também por isso, sem a devida identificação de desejos, vontades e necessidades das pessoas da família e dos sócios. Também por isso, os contratos societários acabam sendo celebrados sem qualquer preocupação com a realização mais eficiente dos objetivos dos sócios, de suas famílias, da própria sociedade, de seus empregados, fornecedores e consumidores. Tudo isso acaba sendo fonte inesgotável de problemas e de conflitos familiares e societários.

Não obstante, pesquisa realizada pela Price Waterhouse Coopers - PWC, entre 29 de abril a 29 de agosto de 2014, em 40 (quarenta) países do mundo, com 2.484 (duas mil quatrocentas e oitenta e quatro) entrevistas de líderes de empresas familiares, apontou que os 
principais problemas enfrentados por essas empresas no âmbito local e mundial, interna e externamente, são os seguintes:

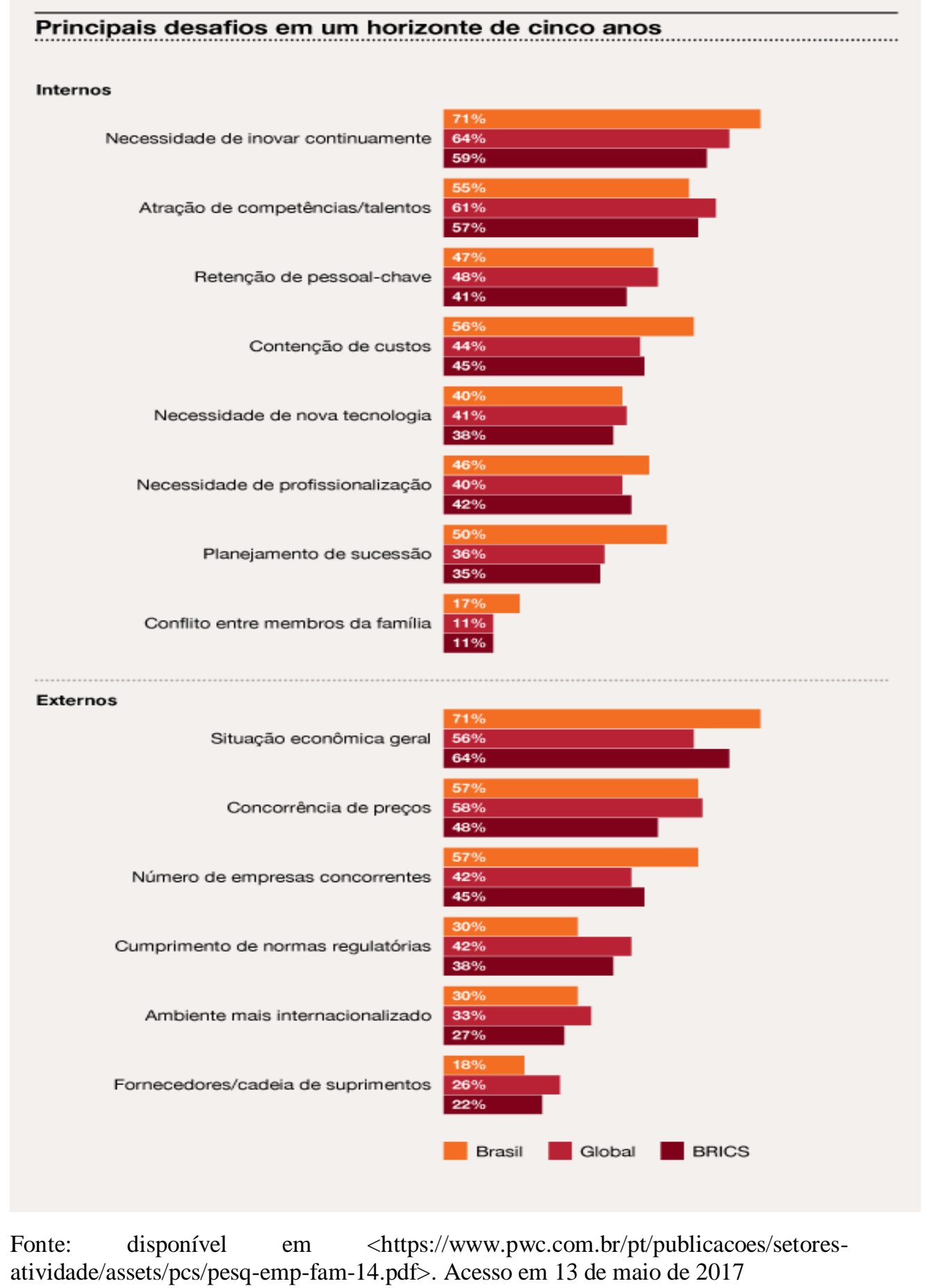

Assim, independentemente dessas conclusões, pode-se indicar como principais problemas jurídicos e societários das empresas familiares, geralmente, os seguintes (quase 
todos relacionados com a necessidade de profissionalização da gestão e com a deficiência de planejamento e de governança formal dessas empresas), dentre outros:

a) ausência de regras claras e prévias relativas ao regime de bens a ser adotado nas uniões estáveis e casamentos da família, bem como relativas à sucessão patrimonial (mobiliária e imobiliária) e à sucessão dos sócios e das principais lideranças na empresa familiar;

b) falta de critérios para ingresso e participação de membros da família nos negócios e na administração da empresa;

c) inexistência de critérios de remuneração dos sócios que trabalham e dos que não trabalham na empresa;

d) inexistência de proibição de pagamento de contas pessoais da família pela empresa;

e) ausência de critérios relativos ao regime de casamento dos sócios e dos seus respectivos herdeiros e sucessores;

f) inexistência e cláusula de não concorrência entre os membros da família (inclusive dos genros e noras) e a empresa familiar;

g) falta de política de formação de sócios, administradores membros da família;

h) inexistência de conselho formal de família e/ou de conselho de administração da empresa familiar (que afaste os sócios do dia a dia da empresa e permita a profissionalização da diretoria).

Todas essas situações, a rigor, precisam ser consideradas tanto no ensino do direito de família e do direito empresarial societário, quanto na prática jurídico-societária, pois são relativamente comuns em grande parte das famílias empreendedoras e das empresas familiares (principalmente, no Brasil) e interferem substancialmente nas estratégias jurídicas e societárias que podem e devem ser desenvolvidas para que os objetivos da empresa, dos seus sócios e da família empreendedora sejam alcançados com a maior eficiência possível, preferencialmente sem conflito e sem processo judicial para dirimi-lo. E o mais interessante é que a maior parte desses problemas familiares e societários somente podem ser resolvidos por meio de planejamento, de estratégia, de entendimentos, de autoconhecimento e, quase sempre, sem o uso de processos judiciais. 
O problema é que o ensino do direito de família e do direito empresarial societário normalmente não é conduzido para preparar o profissional do direito para estruturar juridicamente os objetivos das pessoas da família empreendedora e da empresa familiar, nem tampouco para enfrentar e resolver esses problemas, de forma amigável e sem processo judicial. Todavia, o uso do método Lego Serious Play pode ser um dos caminhos viáveis e interessantes para esse desiderato.

\section{LEGO Serious Play (LSP)}

Inicialmente, antes de adentrar-se no estudo e explanações específicas do método LEGO Serious Play (LSP) e de como ele pode ser usado na estruturação eficiente dos objetivos das pessoas das famílias empreendedoras, ou na prevenção e na solução de problemas familiares e societários, é imperioso analisar, ainda que brevemente, os principais aspectos e características do instrucionismo, do construtivismo e do construcionismo. Isso é necessário, sobretudo, para compreender e conectar a realidade atual dos cursos jurídicos no Brasil, com a necessidade de estudo, de desenvolvimento e de implementação de metodologias e métodos inovadores tanto para o ensino jurídico estratégico (voltado para a estruturação jurídica dos objetivos das pessoas), quanto para a solução efetiva dos problemas jurídicos reais da vidas das pessoas e da sociedade.

Na realidade, os cursos jurídicos do Brasil continuam sendo desenvolvidos a partir da lógica do conflito e do processo judicial (GABRICH, 2010). E isso é evidente nas diretrizes curriculares da maioria das disciplinas dos cursos de Direito, o que também corre no direito de família e no direito empresarial.

Tal característica está intrinsecamente ligada ao caráter fundamentalmente instrucionista da docência jurídica, que pauta-se, quase exclusivamente, na leitura do texto da lei, na explanação de conceitos (e quase nunca da finalidade dos institutos jurídicos), no pressuposto de um conflito (que precisa ser solucionado ou prevenido), no saber quase que exclusivo dos professores, desenvolvido por meio de um discurso dogmático e unidirecional.

De fato, o instrucionismo é uma metodologia de ensino que consiste na transmissão de conteúdos fundamentalmente por meio de aulas expositivas e unidirecionais (monólogos), numa abordagem linear e dogmática, na qual exige-se do aluno a memorização e reprodução do conteúdo repassado pelo professor. Portanto, no instrucionismo o discente tem um papel 
passivo (escutar, assimilar e decorar as informações), ao passo que o docente é o polo ativo e o centro da sala de aula.

Contudo, é evidente que o instrucionismo é importante para a educação, tanto que ainda é o modelo mais aplicado na maioria das escolas e universidades, e a principal metodologia que permitiu o desenvolvimento do conhecimento alcançado pela humanidade até o momento.

Porém, o uso excessivo e quase exclusivo desse modelo está desconectado com as inovações, com o fluxo contínuo e livre de informações, bem como com o pluralismo de ideias e de concepções de ensino e de aprendizagem determinados pela era do conhecimento que marca este século.

Não obstante, para instigar o interesse do discente, bem como para deslocar o aluno do polo passivo (de mero receptor de informações e conteúdos) e despertá-lo para o aprendizado, é imprescindível repensar o ensino jurídico, bem como a pesquisa e a implementação de variadas e inovadoras metodologias e métodos de ensino. Nesse sentido, o construtivismo e o construcionismo são metodologias importantes para essa necessária evolução.

O construtivismo, desenvolvido por Jean Piaget, busca entender o processo de aprendizagem do indivíduo; estuda o papel ativo do sujeito na construção dos novos conhecimentos, que se dá através das experiências e interações da pessoa com o mundo. Entretanto, vale observar, Piaget limitou as suas pesquisas ao processo de aprendizado infantil.

Nesse sentido, segundo Fernando Becker:

Construtivismo significa isto: a ideia de que nada, a rigor, está pronto, acabado e de que, especificamente, o conhecimento não é um dado, em nenhuma instância, como algo terminado. Ele constitui pela interação do indivíduo com o meio físico e social, com o simbolismo humano, com o mundo das relações sociais; e se constitui por força de sua ação e não por qualquer outra dotação prévia, na bagagem hereditária ou no meio, de tal modo que podemos afirmar que antes da ação não há psiquismo nem consciência e, muito menos, pensamento (BECKER, 1993, p. 88-89).

Já o construcionismo, desenvolvido por Seymour Papert, é uma extensão ou uma evolução do construtivismo. Papert buscou criar um ambiente mais favorável às teorias de Piaget, bem como ampliou os destinatários da pesquisa, ultrapassou o universo do ensino infantil e preocupou-se, também, com a educação dos adultos, bem como com a necessidade 
de criar ambientes que favoreçam os aprendizes a serem construtores ativos do processo de conhecimento.

KRISTIANSEN e RASMUSSEN (2015, p.84) explicam que Papert enxergava os ambientes escolares convencionais como muito estéreis, passivos e dominados pela instrução; pois eles não promoviam uma atmosfera que permitia às crianças serem construtoras ativas de seu conhecimento (algo que eles sabiam que elas eram). Os mesmos autores aprofundaram os estudos de Papert e pesquisaram, também, como o cérebro humano aprende, bem como é possível potencializar os insights e desenvolver a criatividade, além de como solucionar problemas, como obter participação ativa e integral das pessoas. Foi assim que desenvolveram o método LEGO Serious Play (que é um método pautado na metodologia construcionista de Papert) na empresa dinamarquesa LEGO.

Os criadores do método perceberam que para maximizar o potencial humano é preciso desenvolver um pensamento estratégico, aguçar a criatividade, a imaginação e os sentidos, permitindo, assim, um pensamento inovador.

Inicialmente desenvolvido para auxiliar o desenvolvimento de estratégias empresariais e a tomada de decisões nas organizações, o LSP sempre teve em sua essência a criatividade e a imaginação. De fato, no início dos anos 1990, Robert Rasmussen começou a investigar como poderia aplicar os seus conhecimentos sobre como crianças aprendem e daí elaborar algo para que os adultos pudessem desenvolver estratégias. Em 2001 o LSP teve sua primeira versão como uma "técnica de pensamento, comunicação e resolução de problemas para grupos" e se disseminou pelo mundo, com inúmeros aprendizados e rearranjos, sendo significativamente mais sofisticado hoje e aplicado em diversos segmentos, inclusive o educacional.

O desenvolvimento da metodologia LEGO Serious Play acabou demonstrando que é preciso engajar as pessoas (alunos) e permitir que todas $(100 \%)^{5}$ participem dos processos de construção do conhecimento e das atividades, pois só assim é possível elevar o rendimento da equipe (sala de aula) e o nível de compreensão de cada conteúdo.

Para isso, é preciso criar um ambiente que permita que pessoas (alunos) estejam engajadas, estimuladas, com liberdade para criar, para inovar (e inclusive errar) e para

\footnotetext{
${ }^{5}$ Os criadores do método LSP buscavam alternativas para eliminar as famosas e frequentes "Reuniões 20/80", que são aquelas onde $20 \%$ dos presentes se expressam e $80 \%$ ficam calados. Fato muito comum nas salas de aulas dos cursos jurídicos do Brasil.
} 
conseguir expelir, inclusive, o que elas não sabem que sabem, pois, como afirma Rasmussen (2015, p.18): as próprias pessoas normalmente sequer sabem o que elas sabem.

De fato, o método LEGO Serious Play, extremamente motivacional e participativo, é baseado no construcionismo de Papert e combate os desafios atuais relacionados com o desinteresse dos alunos pelas aulas marcadamente expositivas e instrutivistas (que ainda prevalecem, infelizmente, no ensino jurídico), que acabam não os preparando adequadamente para estruturarem juridicamente os objetivos das pessoas (preferencialmente sem conflito e sem processo judicial). O método proporciona agregação e participação dos alunos e professores, pois todos são importantes e podem contribuir para o processo de ensino e de aprendizagem. Além disso, o LEGO Serious Play potencializa insights (ideias novas, às vezes desconhecidas dos próprios participantes e que são expelidas subitamente durante o desenvolvimento das atividades), aumenta a confiança e o comprometimento de todos os sujeitos do processo de educação, pois permite a vivência e a experiência do conhecimento (KRISTIANSEN; RASMUSSEN, 2015, p.23).

Basicamente, o método do LEGO Serious Play é desenvolvido com uso de metáforas (que podem gerar maneiras radicalmente novas de entender as coisas, pelo seu papel ativo, construtivo e criativo na cognição humana) e com fundamento na empatia (que permite aos participantes se colocarem no lugar das pessoas envolvidas com o tema-problema apresentado pelo professor, facilitando a construção de soluções inovadoras e possíveis).

LEGO Serious Play não é um brinquedo, mas uma metodologia voltada para geração de ideias, para a inovação, para o conhecimento e para a aprendizagem baseada na construção literal de modelos palpáveis que representem a efetiva solução dos problemas reais das pessoas. A metodologia pressupõe que as pessoas são mais inovadoras e aprendem mais quando "pensam com as mãos" e constroem a solução de problemas relacionados realmente com as suas vidas. LEGO Serious Play ${ }^{6}$ é uma metodologia com propósito explícito e específico que auxilia em construções que gerem reflexões e experiência pessoal.

\footnotetext{
${ }^{6}$ Serious Play é um "jogo sério" tem um propósito explícito e acontece de forma específica. Este propósito é tratar um assunto real com os participantes ao redor de uma mesa por meio do engajamento deles, desbloqueio de seus conhecimentos e quebra do pensamento convencional. Como explicam KRISTIANSEN e RASMUSSEN (2015, p.41): Os participantes sabem que utilizarão sua imaginação - isto é, sua habilidade para formar uma imagem mental de algo que ainda não existe - para antecipar coisas que ainda não aconteceram. Eles estão explorando um estado plausivel e possível ou vendo a realidade atual de uma maneira diferente além de entender sua complexidade e incerteza de forma diferente. Ou seja, permite que os participantes (alunos) desenvolvam o seu senso-crítico e pensem de maneira divergente, "fora da caixa". Os participantes se engajam no jogo para aprender, gerar opções e desenvolver um novo entendimento juntos. Realizam um processo que os prepara para tomarem decisões melhores, e isto alinha seus objetivos e pontos de ação e gera novos
} 
Além de estar baseada na metodologia construcionista que, como supracitado, foi desenvolvido por Seymour Papert, o método do LEGO Serious Play tem também como pressuposto o PBL (Problem-Based Learning), ou aprendizagem baseada em problemas.

De fato, a aprendizagem baseada em problemas é conhecida mundialmente como um método de ensino-aprendizagem caracterizado pelo uso de problemas da vida real para estimular o desenvolvimento do pensamento crítico e das habilidades de solução de problemas e a aquisição de conceitos fundamentais da área de conhecimento em questão (RIBEIRO, 2008).

O PBL originou-se na escola de Medicina da Universidade de McMaster (Canadá) no final dos anos 1960, inspirado no método de casos de ensino da escola de Direito da Universidade de Harvard (USA), justamente em resposta à insatisfação e ao tedio dos alunos frente ao grande volume de conhecimentos percebidos como irrelevantes à prática médica (o que é comum na educação de outros cursos, inclusive o de Direito) (RIBEIRO, 2008).

O PBL é uma metodologia de ensino que busca uma formação que integre a teoria à prática, bem como o mundo acadêmico ao mercado de trabalho, promovendo o desenvolvimento de habilidades e atitudes profissionais e cidadãs.

Segundo RIBEIRO (2008) a principal característica do PBL é que o método utiliza um problema para iniciar, direcionar, motivar e focar a aprendizagem, diferentemente dos demais métodos convencionais, que normalmente utilizam problemas de forma pontual ou apenas depois da aula fundamentalmente expositiva.

Trata-se de um método colaborativo, construtivista e contextualizado, no qual situações-problema são utilizadas para iniciar, direcionar e motivar a aprendizagem de conceitos, teorias e o desenvolvimento de habilidades e atitudes no contexto da sala de aula.

A aprendizagem baseada em problemas promove, assim, o ensino significativo de conhecimentos, proporcionando uma aprendizagem ativa, centrada nos discentes e que contempla o trabalho de grupos pequenos de alunos que são facilitados por tutores (o professor é um facilitador do processo de aprendizagem).

aprendizados. O desafio e capacidade de imaginação que o método LSP e o próprio jogo propiciam ajuda a quebrar o padrão de pensamento e encoraja os envolvidos a utilizar livremente sua imaginação.

O LSP é uma abordagem de pensamento, comunicação e resolução de problemas para tópicos que são reais para os participantes, sendo uma preparação dos sujeitos para o sucesso. (KRISTIANSEN e RASMUSSEN, 2015, p.42-46). 
O LEGO Serious Play apresenta e se utiliza dessas características e diferenciais do PBL, para promover o aprendizado ativo, significativo, crítico, criativo, estratégico e efetivo. Nesse sentido, é importante observar que o LEGO Serious Play utiliza situações-problema (PBL) no inicio do processo desenvolvido em cada sessão/aula, para instigar a criatividade e desafiar os participantes/alunos na elaboração de estratégias voltadas para estruturação eficiente dos objetivos das pessoas envolvidas na situação, bem como soluções e respostas concretas para os problemas apresentados, construídas a partir das peças de LEGO, em três dimensões.

Para isso, preferencialmente, os participantes devem possuir conhecimento mínimo acerca do tema-problema, para que tenham melhores condições para o desenvolvimento das soluções que o problema colocado requer. E isso pode ser obtido por meio de textos, livros e vídeos disponibilizados pelo professor antes do uso do método, caso o tema-problema não tenha correlação direta com os conhecimentos e experiências pretéritas dos participantes.

Antes do início e da distribuição das peças de LEGO, o professor deve dividir a turma em grupos de quatro a cinco pessoas, e deve demonstrar a "etiqueta" do método LEGO Serious Play, segundo a qual, em virtude do uso de metáforas e da empatia, todos devem participar e saber que não existem respostas absolutamente certas ou erradas para os problemas apresentados, mas "apenas" respostas significativas, que devem ser interpretadas e discutidas pelos alunos.

Formados os grupos, o professor deve, primeiro, desenvolver uma atividade para que os participantes conheçam as peças LEGO e possa interagir com elas, como, por exemplo, atribuir um tempo para que os participantes individualmente construam a maior torre possível, ou para que representem com as peças as suas histórias pessoais mais significativas ou curiosas, para que sejam apresentadas para o grupo e para os demais alunos.

Em seguida, o professor deve apresentar o(s) tema(s)-problema(s) para os grupos (que pode ser um único ou vários que tenham interconexão) e pedir, primeiro, que os participantes construam com as peças LEGO as suas soluções individuais, para que sejam apresentadas em seus próprios grupos.

$\mathrm{Na}$ sequência, a partir das respostas individuais e debates decorrentes, o professor deve solicitar ao grupo que desenvolva outro modelo com as peças de LEGO, que represente uma solução decorrente do entendimento do grupo. 
No final, especialmente quando os problemas dos grupos são relacionados e interconectados, o professor deve solicitar que os grupos encontrem e desenvolvam as conexões entre os modelos criados em cada grupo, de maneira a evidenciar a importância das soluções sistêmicas, holísticas e sustentáveis.

Conforme retro mencionado, essas etapas de aplicação e etiqueta do método LSP (LEGO Serious Play) são a base de aplicação para o desenvolvimento do aprendizado pleno, com uso do LSP. Assim, tendo em vista que o presente trabalho científico limita-se à aplicação do LSP na solução de problemas familiares e societários, segue abaixo abordagem específica do aludido tema.

\subsection{LEGO SERIOUS PLAY NA SOLUÇÃO DE PROBLEMAS FAMILIARES E SOCIETÁRIOS}

O ensino e a prática jurídica brasileira, indiscutivelmente, passam por uma crise que pode ser analisada a partir de diversos aspectos ideológicos, sociais, culturais, econômicos, políticos e metodológicos, sendo que a esta pesquisa, por conta de um corte epistemológico, somente interessam os aspectos metodológicos do LEGO Serious Play, que podem ser usados para evolução do ensino do direito de família e do direito empresarial, e que esse ensino seja especificamente voltado para a estruturação de objetivos reais e para a solução de problemas das famílias empresárias e de suas respectivas sociedades familiares.

Assim, como restou demonstrado acima, os principais problemas enfrentados pelas famílias empresárias e pelas suas respectivas sociedades, são os seguintes:

a) ausência de regras claras e prévias relativas ao regime de bens a ser adotado nas uniões estáveis e casamentos da família, bem como relativas à sucessão patrimonial (mobiliária e imobiliária) e à sucessão dos sócios e das principais lideranças na empresa familiar;

b) falta de critérios para ingresso e participação de membros da família nos negócios e na administração da empresa;

c) inexistência de critérios de remuneração dos sócios que trabalham e dos que não trabalham na empresa; 
d) inexistência de proibição de pagamento de contas pessoais da família pela empresa;

e) ausência de critérios relativos ao regime de casamento dos sócios e dos seus respectivos herdeiros e sucessores;

f) inexistência e cláusula de não concorrência entre os membros da família (inclusive dos genros e noras) e a empresa familiar;

g) falta de política de formação de sócios, administradores membros da família;

h) inexistência de conselho formal de família e/ou de conselho de administração da empresa familiar (que afaste os sócios do dia a dia da empresa e permita a profissionalização da diretoria).

Em virtude desses problemas, o principais objetivos das famílias empreendedoras e de suas empresas familiares, são os seguintes, dentre outros:

a) garantir que eventuais dívidas das sociedades não contaminem o patrimônio das pessoas da família e vice-versa;

b) garantir que o eventual desfazimento de uma união estável ou de um casamento, não interfira significativa, administrativa e patrimonialmente nas empresas familiares;

c) estabelecer regras claras de convivência das pessoas da família e delas com as sociedades familiares das quais elas são sócias;

d) garantir o aprimoramento da gestão da empresa familiar, por meio da preparação de sucessores da família ou da profissionalização;

e) estabelecer a independência contábil e financeira da família e das sociedades familiares;

f) permitir a sucessão empresarial e patrimonial, observada a sustentabilidade da família empreendedora e da sociedade familiar.

De fato, o método LEGO Serious Play pode ser usado para o ensino do direito de família e do direito empresarial societário, para que os alunos (futuros profissionais do direito) sejam treinados para desenvolverem estratégias jurídicas eficientes para a melhor 
realização dos objetivos acima traçados, preferencialmente sem a existência de conflitos e sem processos judicias para solucioná-los.

Da mesma maneira, o método LSP pode e deve ser usado pelos profissionais do direito (advogados, juízes, promotores) para que, junto com os seus clientes e jurisdicionados, possam desenvolver estratégias jurídicas eficientes para realização dos objetivos das famílias empreendedoras e suas sociedades familiares, bem como para solucionar os seus problemas.

$\mathrm{Na}$ realidade, o cérebro trabalha melhor com as mãos, e existe uma evidencia ${ }^{7}$ bem fundamentada sobre a profunda interdependência entre a mão e o cérebro, sendo ambos, centrais para o desenvolvimento humano. Além disso, como já evidenciado nessa pesquisa, Jean Piaget comprovou que a inteligência cresce da interação entre o cérebro e o mundo (conhecimento é fruto das experiências com o mundo, é uma operação que constrói os seus objetivos). Assim, de um modo primário, como ensina RASMUSSEM (2015), o cérebro utiliza as mãos para construir seu próprio conhecimento de mundo.

Para Papert, o pensamento concreto (muito usado em crianças) é um modo complementar aos modos de reflexão mais formais e abstratos, e deve ser desenvolvido em qualquer estágio de aprendizagem (qualquer idade, cultura, idioma), pois é um meio valioso de pensamento e de construção de caminhos para o conhecimento, principalmente por desbloqueá-los. O pensamento concreto é uma forma universal da razão humana e permite resultados mais rápidos e com mais confiança e compreensão do que representações abstratas e formais.

E é justamente com essa perspectiva que o método LSP se desenvolve, pautado no pensamento concreto e radiante (não linear e marcadamente emocional), com uma comunicação imagética significativa, que desbloqueia novos conhecimentos e torna o aprendizado memorável.

Por isso, o método LSP pode e deve ser aplicado no ensino e na prática jurídica, pois garante a devida conexão entre teoria e prática, entre razão e emoção, bem como a devida interação entre os conhecimentos dos alunos e dos professores, bem como dos profissionais do direito e seus clientes. Trata-se de uma técnica educacional e em um método de trabalho

\footnotetext{
${ }^{7}$ Sobre o tema recomenda-se a leitura dos trabalhos dos antropologistas e paleontologos Louis e Mary Laekey; Richard Leakey (filho); Donald Johanson e Sherwood Washburn, que apontam aprofunda interdependência entre a mão e o cérebro. O neurocirurgião canadense Wilder Penfield (1891 - 1976) também demonstrou em suas pesquisas a ligação íntima entre o cérebro e a mão no desenvolvimento humano, comprovada pelo mapa do cérebro desenvolvido por Penfield que mostra as proporções do cérebro dedicadas a controlar as diferentes partes do corpo, evidenciando que grande parte é destinada à mão. (KRISTIANEN; RASMUSSEN, 2015, p.92).
} 
interessado no aprendizado e na solução de problemas pela ação, no qual todos os participantes estão ativos, engajados e contribuem com o processo de aprendizagem e/ou solução de problemas, o que maximiza a participação, o interesse e a estruturação conjunta de objetivos e/ou a solução de problemas das famílias empreendedoras e de suas empresas familiares.

A aplicação do método LEGO Serious Play, seja em aulas e/ou nas atividades da profissão jurídica, tem significativa eficiência, principalmente na estruturação eficiente de objetivos e na solução de problemas familiares e societários, pois permite que as pessoas vivenciem os contextos explorados e consigam desbloquear conhecimentos, alcançando soluções reais para os objetivos e problemas colocados em discussão. Tudo mediante a representação de ideias e insights por meio das peças de LEGO.

Para o desenvolvimento do método, após a divisão dos alunos e/ou clientes em grupos, da demonstração da etiqueta do LEGO Serious Play (empatia, metáfora, inexistência de resposta certa ou errada, mas, sim, significativa) e da realização das atividades de interação (tal como demonstrado acima), o professor ou profissional do direito deverá construir e apresentar a história (fictícia no caso das aulas e real no caso da atuação profissional como advogado, juiz ou promotor), dividindo entre os grupos a responsabilidade pela estruturação de objetivos e/ou solução dos problemas dos personagens da história.

Sempre a história deve ser construída também de forma que os grupos considerem sempre a necessidade de a aula ou trabalho ser desenvolvido para a estruturação dos objetivos e de solução dos problemas das famílias empreendedoras e de suas respectivas sociedades familiares, em um contexto viável e sustentável do ponto de vista familiar, econômico, financeiro, negocial e jurídico.

Em seguida, o professor e/ou profissional do direito deve solicitar que cada grupo represente em peças de LEGO, até duas estratégias jurídicas viáveis para que os objetivos do personagem do grupo sejam alcançados com a maior eficiência possível, sem conflito e/ou minimizando as chances de um processo judicial.

Na sequência, o professor e/ou profissional do direito deve permitir que cada grupo apresente aos demais grupos os objetivos reais do personagem e as estratégias construídas pelo grupo, sempre por meio da apresentação do modelo construído com peças de LEGO.

Ato contínuo, o professor e/ou profissional do direito deve permitir que os grupos debatam e separem as estratégias familiares, financeiras e jurídicas adotadas que podem ser 
conectadas umas com as outras e as estratégicas inconciliáveis com as demais, de maneira a permitir a maior harmonia familiar e jurídica possível no caso proposto.

Finalmente, com a participação do professor e/ou do profissional do direito, todos devem conectar todos os modelos LEGO construídos pelos grupos e explicitar em um documento, um vídeo ou uma ata do workshop (ou aula/reunião) por exemplo, as estratégias e soluções construídas pelo grupo para a família empreendedora e por suas respectivas empresas familiares.

Essas são importantes etapas para o bom desenvolvimento e aplicação do método LSP no ensino e na prática jurídica, especialmente no âmbito do direito de família e do direito empresarial societário.

De qualquer maneira, é importante ressaltar que dentre os inúmeros resultados, êxitos e benefícios do método LEGO Serious Play, KRISTIANSEM e RASMUSSEM (2015), bem como os autores deste artigo científico (por meio das experiências já realizadas com o LSP em suas atividades profissionais e nos cursos de graduação e de mestrado em Direito), evidenciam o seguinte.

O método LEGO Serious Play: a) coloca todos os participantes no mesmo nível, independentemente de qualquer hierarquia acadêmica, familiar ou empresarial; b) mantém todas as pessoas envolvidas continuamente e ativamente durante a atividade; c) encoraja as pessoas a revelarem ideias autênticas; d) dificulta a influência de opiniões e perspectivas individuais sobre objetivo geral; e) estimula o desenvolvimento participativo da comunicação; f) prioriza o autoaprendizado e a autocomposição de soluções viáveis para os problemas das pessoas da família empreendedora e da sociedade familiar; g) estimula o aprendizado, a estruturação de objetivos e a solução de problemas por meio ação; h) expande os horizontes, e proporciona a quebra de paradigmas convencionais; i) desbloqueia novos conhecimentos (inclusive os que as pessoas não sabem que possuem); j) auxilia os participantes a descontruírem o que seria uma situação altamente complexa (permite uma visão do todo); $\mathrm{k}$ ) contribui para a concentração e interesse dos participantes; 1) o LSP é ainda mais eficiente quando o desafio é complexo e sem soluções óbvias (o que normalmente acontece com as famílias empreendedoras e com as sociedades familiares, e aumenta senso critico dos participantes); m) os participantes acumulam experiências ao realizarem as atividades ativamente, fortalecendo a compreensão do conteúdo e alcançando a cognição efetiva; $n$ ) contribui para aumentar a inteligência coletiva dos participantes, além de estimular o espírito 
de trabalho em equipe, de interação e colaboração social; o) o cérebro aprende melhor com as mãos e o LSP trabalha ativamente a conexão desses dois componentes centrais do desenvolvimento e aprendizado humano; p) é aplicável e funciona para todas as pessoas (tanto em crianças, quanto em adultos de qualquer faixa etária), bem como em qualquer idioma e cultura; q) é um método que trabalha não o que você já sabe conscientemente, pelo contrário, é desenvolvido para desbloquear novos conhecimentos e por isso é capaz de resultar em uma grande transformação da educação e cognição humana; r) permite a mudança de comportamento (quando os participantes estão sendo observados, eles normalmente irão consciente ou inconscientemente mudar o seu comportamento); s) o LSP prepara o participante para saber se adaptar às situações inesperadas (inclusive na família empreendedora e na sociedade familiar); t) o LSP gera valor para as pessoas e aumenta a confiança, a participação e o comprometimento de todos envolvidos; u) estimula o pensamento estratégico, aguça a criatividade, a imaginação e os sentidos, permitindo, assim, um pensamento inovador e concreto; v) permite que todos os participantes experimentem e vivenciem o conhecimento; $x$ ) fortalece o ensino, a estruturação de objetivos e a solução de problemas pautada na razão e na emoção, com uso da criatividade, sensibilidade e reflexões, maximizando o conhecimento e o desenvolvimento das pessoas, com resgate do ser Humano (GABRICH; BENEDITO, 2016).

Por tudo isso, o LSP é um método que pode e deve ser considerado tanto no ensino, quanto na prática jurídica no direito de família e no direito empresarial societário.

\section{CONCLUSÕES}

Como restou demonstrado nesta pesquisa, as famílias empreendedoras e as empresas familiares enfrentam muitos problemas jurídicos e societários, decorrentes de fatos jurídicos relativamente comuns a todas elas, que decorrem, sobretudo, da falta de planejamento jurídico, da deficiência das regras de governança e da gestão pouco profissional dos negócios.

A maioria absoluta desses problemas pode e deve ser resolvida por meio extrajudicial e fundamentalmente pelo autoconhecimento e pela autocomposição dos próprios sócios e familiares.

Isso normalmente não é ensinado nos cursos de direito de família e de direito empresarial societário, que precisam evoluir para a devida consideração do modelo mental da 
análise estratégica do direito (que considera o direito instrumento para realização eficaz dos objetivo das pessoas, sem conflito e sem processo judicial), e para utilização de metodologias e métodos de ensino, que favoreçam não apenas a solução dos problemas familiares e societários, mas também a construção dessas soluções pelas próprias partes envolvidas.

Como tudo isso não é ensinado, acaba não sendo usado também na atuação dos profissionais do direito (advogados, juízes, promotores) que atuam no âmbito do direito de família e do direito empresarial societário.

A pesquisa demonstrou que o Lego Serious Play pode ser considerado um dos métodos possíveis e viáveis para a melhor estruturação dos objetivos e para a solução de problemas familiares e societários, por meio da metodologia construcionista e do uso do ensino e da atuação profissional baseadas na solução de problemas reais das pessoas das famílias empreendedoras e de suas respectivas empresas familiares.

\section{REFERÊNCIAS}

BECKER, Fernando. O que é construtivismo? In: BORJA, Amélia de et al. Construtivismo em revista. São Paulo: FDE, 1993. p. 87-93 (Série Idéias, 20).

BENEDITO, Luiza Machado Farhat. LEGO Serious Play no Ensino Jurídico. Belo Horizonte: Universidade Fumec, 2017.

BRASIL. Lei 10.406, de 10 de janeiro de 2002. Código Civil Brasileiro. Diário Oficial da União, 10 jan. 2002; com alterações. Disponível em: <http://www.planalto.gov.br/ccivil_03/leis/2002/110406.htm> . Acesso em: 17 mar. 2017.

BUZAN, Tony. Mapas Mentais: métodos criativos para estimular o raciocínio e usar ao máximo o potencial do seu cérebro. Rio de Janeiro: Sextante, 2009.

FERNANDINO, Matheus Bonaccorsi. Governança jurídica nas empresas familiares. Belo Horizonte: Del Rey, 2016.

FREIRE, Paulo. Pedagogia da autonomia: saberes necessários à prática educativa. 51. ed. São Paulo: Paz e Terra, 2015.

GABRICH, Frederico de Andrade. Análise Estratégica do Direito. Belo Horizonte: Universidade Fumec, 2010.

GABRICH, Frederico de Andrade; BENEDITO, Luiza Machado Farhat. Lego Serious Play no Direito. Revista de Pesquisa e Educação Jurídica, v.2, n.2, 2016, p.105-126. Disponível em: < http://indexlaw.org/index.php/rpej/article/view/1310/pdf > . Acesso em: 03 abr. 2017. 
KRISTIANSEN, PER; RASMUSSEN, Robert. Construindo um negócio melhor com a utilização do Método LEGO Serious Play. São Paulo: DVS editora, 2015.

LEGO Group. The science of lego serious play. 2002. Disponível em: www.seriousplay.com Acesso em: 17 mar. 2017.

MORIN, Edgar. Os sete saberes necessários à educação do futuro [livro eletrônico]. São Paulo: Cortez; Brasília: Unesco, 2013.

MUSSIO, Simone Cristina; VALIDÓRIO, Valéria Cristiane; MERLINI, Véra Maria Ferro. As novas tecnologias acopladas à educação: Reflexões sobre o ensino-aprendizagem no século XXI. Revista RETC, n. 14, p. 44-52, abr. 2014. Disponível em: <http://revistafatecjd.com.br/retc/index.php/RETC/article/view/127/pdf >. Acesso em: 3 abr. 2017.

RIBEIRO, Luis Roberto de Camargo. Aprendizagem baseada em problemas (PBL): uma experiência no ensino superior [livro eletrônico]. São Carlos: EdUFSCar, 2008.

SASS, Odair. Construtivismo e Currículo. Artigo digital. Disponível em: http://www.crmariocovas.sp.gov.br/pdf/ideias_26_p087-103_c.pdf . Acesso em: 11 mar. 2016. 